\title{
ANALYSIS OF CURRENT AUTOMATION LEVEL IN SPECIFIC COMPRESSED AIR SYSTEM WITH MODEL FOR OPTIMIZATION
}

\author{
Milovan Medojevic \\ Faculty of Technical Sciences, University of Novi Sad, Trg Dositeja Obradovica 6, Novi Sad 21000, Republic of Serbia
}

\begin{abstract}
Bearing in mind that compressed air is one of the most important utilities for industry, as well one of the largest energy consumers, any savings made in compressed air systems (CAS) have a significant impact on costs effectiveness, energy efficiency and environment. Therefore, the aim of this paper, in addition to literature and good practice guides review, is to provide a close insight on specific compressed air system used to control opening and closure of a large number of windows located at inaccessible places in a large exhibition space in order to propose measures to improve overall system effectiveness and efficiency. Lastly, the current state of previously mentioned CAS automation level is analyzed, based on which a model for its optimization was introduced, while the benefits of such solution are justified.
\end{abstract}

Keywords: Compressed air; system automation; optimization model; effectiveness; efficiency
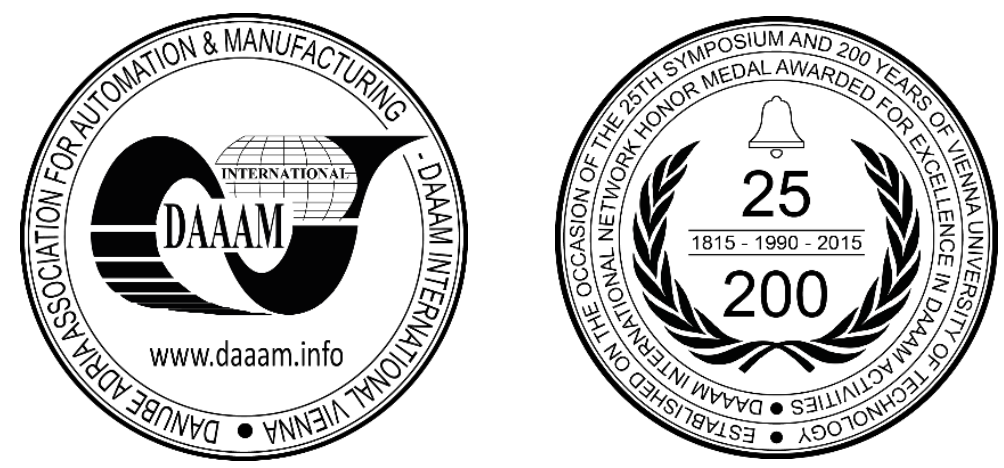

This Publication has to be referred as: Medojevic, M[ilovan] (2016). Analysis of Current Automation Level in Specific Compressed Air System with Model for Optimization, Proceedings of the 26th DAAAM International Symposium, pp.1082-1090, B. Katalinic (Ed.), Published by DAAAM International, ISBN 978-3-902734-07-5, ISSN 1726-9679, Vienna, Austria DOI: $10.2507 / 26$ th.daaam.proceedings. 152 


\section{Introduction}

Bearing in mind that compressed air generation is energy intensive, and for most industrial operations compressing air costs have significant share in overall energy costs $[1,2]$, yet there is a vacuum of reliable information on the energy efficiency of a typical compressed air system (CAS) [3-11]. The inefficiencies inherent in converting energy using a compressed air are well documented, while industry accepts these inefficiencies recognizing other benefits of compressed air utilization $[12,13]$. Inappropriate use, incorrect settings and leaks in the system, as well as human factors in system regulation, lead to the inefficiencies and losses that rapidly accumulate over the system lifetime [14, 15]. Furthermore, knowing that approximately $70 \%$ of all manufacturers have a CAS [16] which is being used to power a variety of equipment, including machine tools, material handling and separation equipment, spray-painting equipment, etc., indicate the necessity, applicability and importance of these systems in modern industry. Therefore a special attention should be devoted to increase effectiveness, improve energy efficiency, upgrade automation and introduce optimization models to overall system performance.

\subsection{Managing $C A S$}

The overall approach of CAS management is based on the same principles as general energy management. This approach is essential in achieving the maximum reduction in overall system energy consumption [17]. According to variety of previously mentioned studies and good practice guides, reduction of $30 \%$ in energy costs is typical and achievable. However, ensuring energy savings to reduce the cost of providing compressed air at site is not just about the compressor $[18,19]$. It involves periodic auditing in order to achieve efficiency and optimal performance in all segments of the system in general (Figure 1).

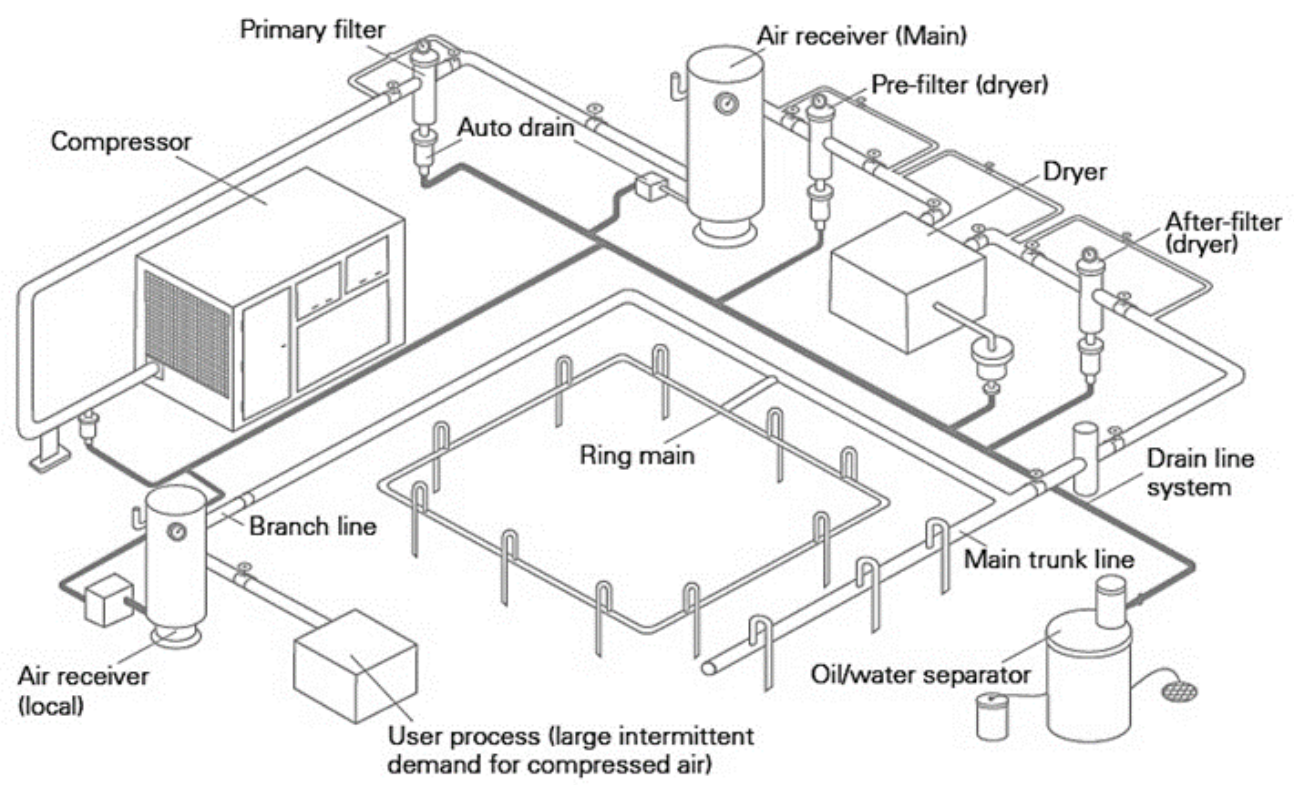

Fig. 1. Typical compressed air system [18].

It is best to start by reviewing end use, because any improvements here may well affect the compressed air demand and the air distribution network (i.e. redundant pipe work and reduced pressure losses) [5,10]. Subsequently, wasting and misuse of compressed air often offer the greatest potential for no or low-cost energy savings in a typical CAS. Therefore, examination and audit of all compressed air application sites is recommended. During the lifetime of an organization, processes evolve and production methods change, thus affecting the way a CAS is maintained, upgraded and therefore the way in which compressed air is used. For these reasons, it is good practice to review the system and working practices regularly. Furthermore, compressed air is used for a myriad of applications due to its safety, flexibility and convenience [12]. However, it is also misused, and hence wasted, for the same reasons, incurring unnecessary costs. In addition, compressed air is often applied just because an air supply is readily available, not because of being the most cost-effective or appropriate method. When it comes to distribution network design, for larger systems with numerous take off points, a ring main is the preferred layout [17]. This is due to the fact that air is supplied to any piece of equipment from two directions, the velocity is halved and the pressure drop reduced. Also, isolation valves could be incorporated to enable specific system sections to be cut off for servicing, maintaining or replacement without interrupting the air distribution to other users and in that way ensuring CAS being more efficient. Some basic but highly effective practical recommendations are summarized in the Table 1. 


\begin{tabular}{cl}
\hline No. & \\
\hline 1. & Identify and repair air leaks, starting with the biggest. \\
2. & Measure and baseline CAS to determine the operating costs and efficiency. \\
3. & Operate compressed air system at the lowest practical pressure. \\
4. & Install, adjust and maintain automatic system controls to coordinate operations of air compressors. \\
5. & Turn off compressed air supply to zones, equipment and applications that are not operating. \\
6. & Use a blower rather than a compressor where and when appropriate. \\
7. & Use air reservoirs to reduce compressor cycling and respond to peak air demands. \\
8. & Use larger diameter pipes and looped air distribution configurations where practical. \\
9. & Maintain compressed air equipment, filters and drains at an appropriate level. \\
10. & Constantly ask if compressed air is the best utility for the intended application. \\
\hline
\end{tabular}

Table 1. Practical recommendations for efficiency improvement of CAS

Finally, it is highly important to involve compressed air operating and maintenance personnel in production and end use decisions.

\section{Description of specific CAS and audit findings}

As an example of observed system, the Hall 1 of the Novi Sad Fair was analyzed. The total area of the fairground is $226000 \mathrm{~m}^{2}$ of which $60000 \mathrm{~m}^{2}$ of area are the pavilions where 37 halls are located. Hall 1 is the largest hall among them covering the area of $4576 \mathrm{~m}^{2}$ which model is presented in the Figure 2. Here, CAS is implemented to control the openness and closeness of a large number of windows, located in inaccessible places (8m high).
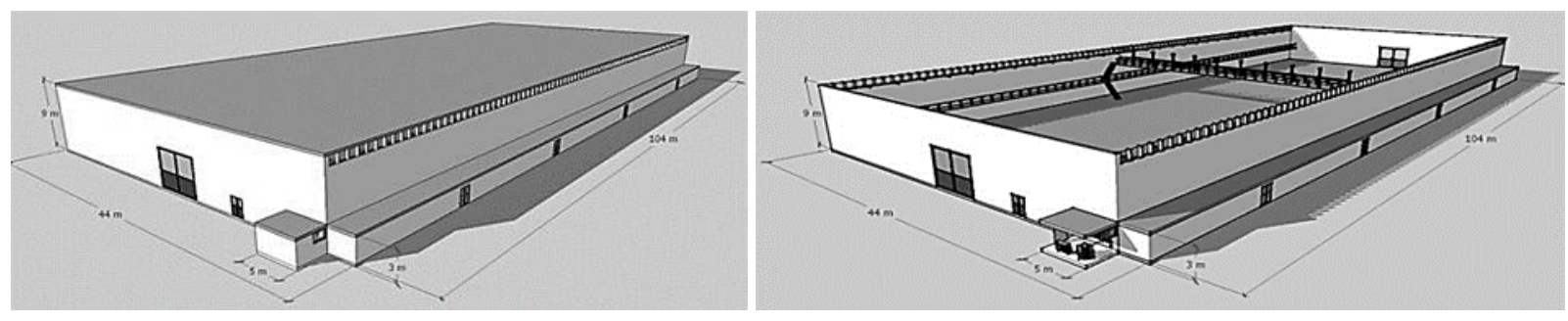

Fig. 2. 3D model of the observed hall - Hall 1

Moreover, the hall has 90 windows on each sidewall where every 3rd window is opened or closed by pneumatic double acting cylinder, which indicate that 60 pneumatic actuators are present on the demand side of the system.

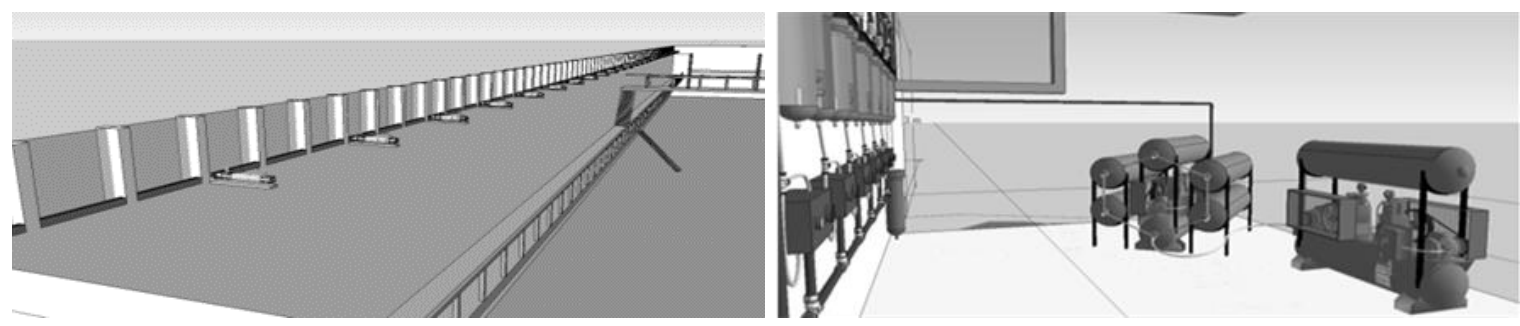

Fig. 3. The setting of the pneumatic actuators (left) and 3D model of the compressor facility (right)

In order to conduct the analysis it was necessary to identify the existing elements of CAS in the hall starting from the production, preparation, distribution and consumption of compressed air. Production of compressed air is carried out by two two-cylinder compressor aggregates (Figure 3 on the right) with overall working volume of $240 \mathrm{~cm} 3$, with working pressure of 8 bars. The number of the air reservoirs on the first aggregate is 2 and on the second 6 , while the volume of each reservoir is 601 . Preparation of compressed air is carried out in 6 air treatment units, consisting of air filter, pressure regulator and air lubricator. In the current system setting, there are several valves in the level of signal processing elements, as well as in the level of the command distributor. In the level of signal elements so called " $3 / 2$ " valves, manually activated, spring returned and normally closed are present. As previously mentioned, in the level of executive elements there are 60 pneumatic actuators without damping at the end of stroke, with $40 \mathrm{~mm}$ piston diameter and $500 \mathrm{~mm}$ piston stroke, working in pressure range from 1.5 to 10 bars. Subsequently, the length of the compressed air distribution pipeline in the observed hall is $173 \mathrm{~m}$, while the calculated equivalent extension of the pipeline due to the appearance of 
resistance to airflow in elements such as the way valves, angle valves, T-branches, elbows, etc., amounts $18 \mathrm{~m}$, resulting in overall pipeline length of $191 \mathrm{~m}$.

\subsection{Current state of system automation}

Due to required relatively low speed of response, a semi-automated pneumatic hardware is used in control systems with slow processes as well as where performance of a very large number of computations is not necessary for execution of a control algorithm, as in the present case. However, in spite of these limitations, the field of application of mentioned hardware is very broad. Given the aforementioned, the current level of automation in the observed CAS is shown in the Figure 4.
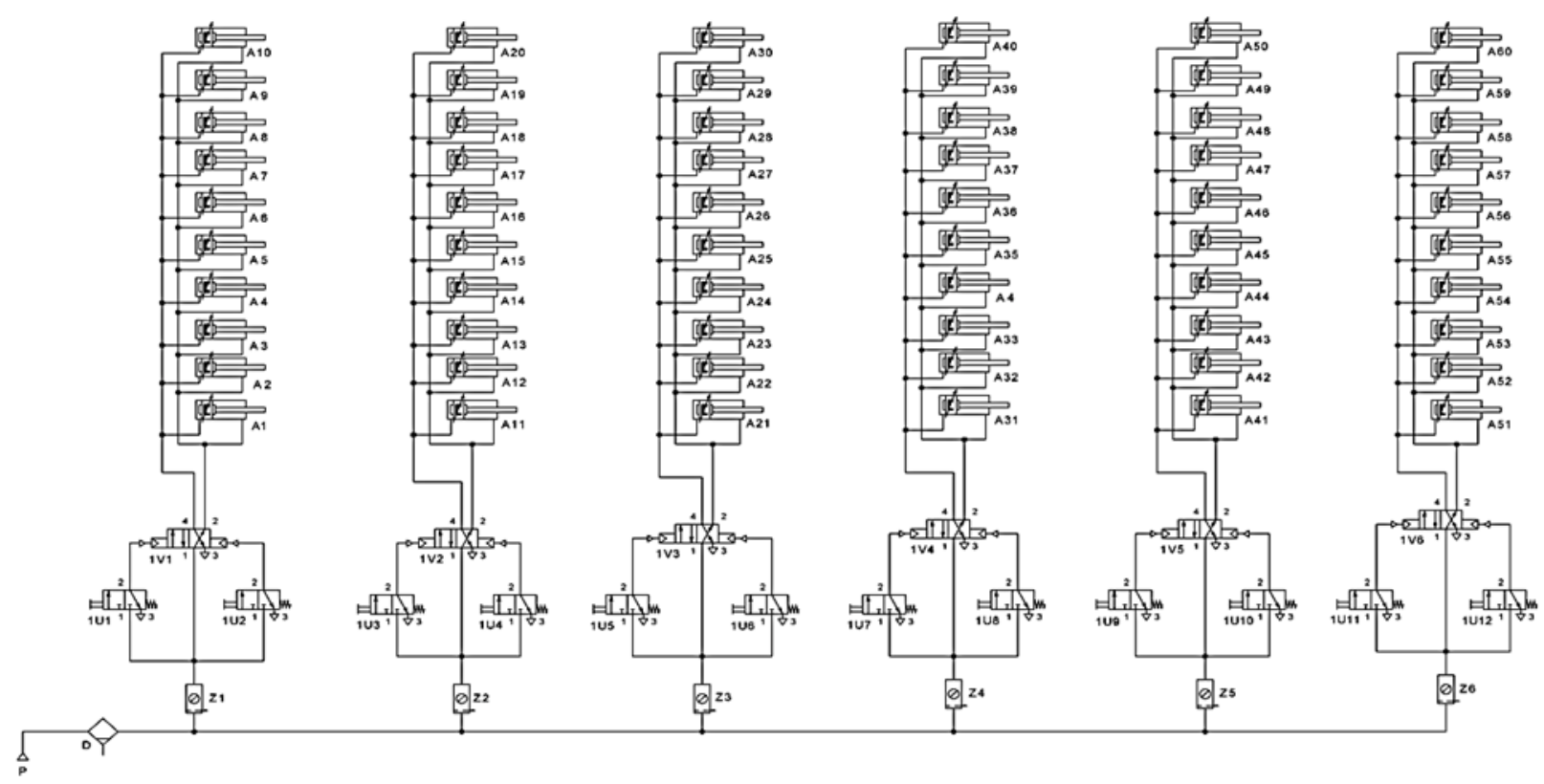

Fig. 4. A current state of CAS automation and pneumatic control scheme

As it can be seen from the Figure 4, production of compressed air is carried out by compressors (P), after which air is being dried in the air dryer (D). Subsequently, dried air is distributed to air preparation units $\left(Z_{1}-Z_{6}\right)$, a combined devices consisting of air filters, pressure regulators and air lubricators. Then, treated and prepared air moves ahead to the level of signal elements $\left(1 \mathrm{U}_{1}-1 \mathrm{U}_{12}\right)$. Having in mind that Figure 4 shows the state of the system where pistons are retracted indicates that the windows are managed closed. By manually activating the signaling valves $1 \mathrm{U}_{1}, 1 \mathrm{U}_{3}, 1 \mathrm{U}_{5}, 1 \mathrm{U}_{7}$, $1 \mathrm{U}_{9}$ and $1 \mathrm{U}_{11}$, changes the position of the command valves $\left(1 \mathrm{~V}_{1}-1 \mathrm{~V}_{6}\right)$, enabling the air way toward the left chambers of actuators $\left(A_{1}-A_{60}\right)$ resulting with extraction of pistons, which indicates that the windows are in the process of opening.

\section{Analysis results}

In the following part of this paper, specific recommendations for efficiency improvement are proposed (section 3.1.). The aforementioned recommendations emerged from the results of conducted audit, analysis of CAS current state, calculation of system elements, and based upon already mentioned literature and best practices in the field. This is followed by introduction of optimization model for observed CAS automation. The model represents a technical solution proposed in order to upgrade automation to a higher level. Here, electro-pneumatic control system, based on $\mathrm{CO}_{2}$ sensors, was designed and simulated. More details are provided in the sections 3.2. and 3.3.

\subsection{Recommendations to boost CAS efficiency}

Based upon the audit results, it was determined that the existing air reservoirs in the observed CAS were not sufficient. More precisely, the air reservoir system was undersized, where the total capacity of existing reservoirs is 0.48 $\mathrm{m}^{3}$, while the recommended reservoir volume, analytically determined should be $0,806 \mathrm{~m}^{3}$. Therefore, the setting of additional air reservoir with capacity of $0.42 \mathrm{~m}^{3}$ is proposed, located just after air dryer. In this way, a good quality system configuration could be achieved providing the system with wet reservoir, air dryer and dry reservoir. According to the studies [20,21], a properly designed air reservoirs play an important role in CAS by allowing the system operation with a smaller pressure difference at a given air consumption as well as with smaller average system pressure, which results in reduced electricity consumption for air compression. In addition, having in mind the manner of system functioning (opening and closing of windows with great ease), i.e. the ascertainment of oversized cylinders, the possible reduction in 
working pressure by 2 bars was estimated. This would significantly reduce the power consumption as the less powerful motor could be installed, ensuring savings of at least $26.6 \%$ in electricity consumption.

\subsection{Optimization model for current CAS automation improvement}

Having in mind that numerous studies [22-28] shown that indoor climate have a significant impact on people's health [27], their productivity [23, 24], cognitive functions and wellbeing [25], a suitable indicator for determining air quality is the concentration of $\mathrm{CO}_{2}$. Normally, the concentration of $\mathrm{CO}_{2}$ in the air increases by breathing. Therefore it is important to measure and control the $\mathrm{CO}_{2}$ concentration in spaces where many people are present (schools, conference halls, exhibition spaces, open offices, etc.). Optimization model of the observed CAS is based on the supplementation of the existing pneumatic installation with adequate elements in order to upgrade it to an adequate level of automation. To achieve this, it is necessary to additionally implement solenoid valves and ensure control based on electrical signals, relays and appropriate sensors. This solution is very simple but also practical and efficient for application in organizations such as this one [29]. Bearing in mind audit results and current state of system automation shown in section 2.1., it is evident that in the current setting there is no possibility to open all windows at once. Furthermore, the regulation is based upon the subjective feeling of the operator while control indicators are not being formed and monitored. Current control and regulation of CAS should be upgraded especially having in mind the fluctuations of people during fair-time are often not predictable. Also, the level of the activity varies as well, resulting in variable $\mathrm{CO}_{2}$ emissions due to the human and animal (during Agricultural fair) metabolic rate. Thereby, the detection of maximum allowed $\mathrm{CO}_{2}$ concentration in the hall could automatically control the openness and closeness of aforementioned windows. Subsequently, due to the difference of air pressure and temperature between outside and inside conditions, natural ventilation occurs and the windows remain open until the sensor detects the set value of $\mathrm{CO}_{2}$ concentration for closing, or until the manually activated valve forces them to close. Also, it was estimated that in $\mathrm{CO}_{2}$-demand controlled ventilation systems the energy consumption of the air conditioning system could be reduced by 20-30\% [30, 31]. The principle of the proposed solution is explained below while the scheme of the solution is shown in the Figure 5. By pressing the button (START) in the electro-pneumatic scheme, the system is under voltage. In this case, the relay (K1) receives a signal and closes the electrical contact (K1), which allows transmission of signal to the sensor (S1) and (S2). When the sensor (S1) detects a preset concentration of $\mathrm{CO}_{2}$ makes contact and enables the transmission of electrical signal to the relay (K2), which closes the contact (K2) in $11^{\text {th }}$ branch of electrical control scheme and passes the electrical signal to the spool (1Y1) of the control valve (1U1) on the pneumatic control scheme and thus changes the position of the same so that compressed air can pass through, change the position of the command valve (1V1) and allow the air a way toward the left ventricles of cylinders, causing pistons to extract (so windows start opening).

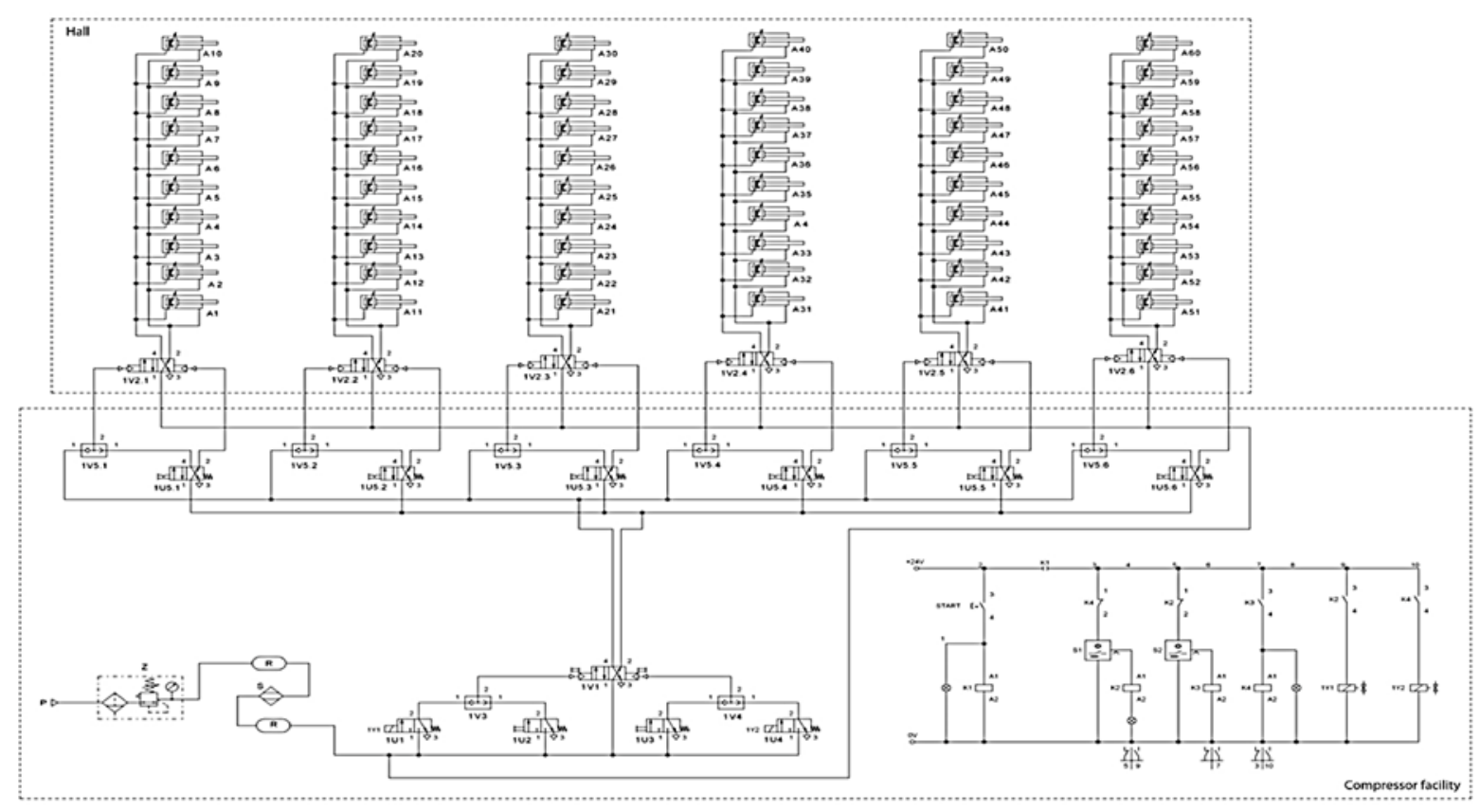

Fig. 5. New, electro-pneumatic control scheme

Likewise, when the sensor $\left(\mathrm{S}_{2}\right)$ detects the previously set concentration of $\mathrm{CO}_{2}$, joins contact and enables the transmission of electrical signal to the relay $\left(\mathrm{K}_{3}\right)$, which in the $9^{\text {th }}$ branch of electrical control scheme, closes the contact $\left(\mathrm{K}_{3}\right)$ so relay $\left(\mathrm{K}_{4}\right)$ receives a signal, enables the switch contact $\left(\mathrm{K}_{4}\right)$ in $12^{\text {th }}$ branch, which enables connection to a spool $\left(1 \mathrm{Y}_{2}\right)$ on the control valve $\left(1 \mathrm{U}_{4}\right)$, changes his position as well as the position of command valve $\left(1 \mathrm{~V}_{1}\right)$, which allow the air to pass into the right ventricles of cylinders, causing pistons to retract (so windows start closing). In case of sensor 
failures, opening of windows is activated manually through control valve $\left(1 \mathrm{U}_{2}\right)$, while closing is achieved by manually activating the control valve $\left(1 \mathrm{U}_{3}\right)$. A closer look on the electrical control scheme is given in the Figure 6.

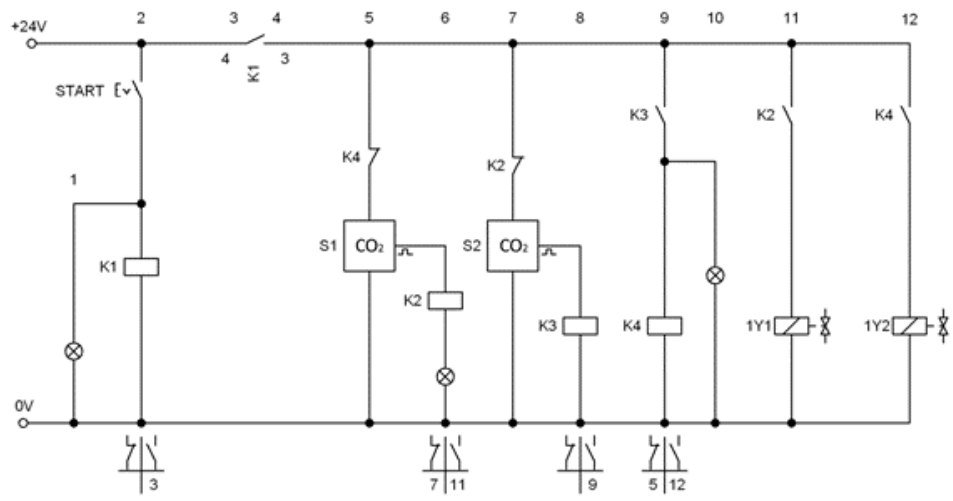

Fig. 6. Electrical control scheme

The Figure 6 provides an insight on sensor positions, relays, switches, spools as well as signaling elements which were introduced to upgrade current automation state of the system.

\subsection{Simulation of proposed solution}

The initial state of the system under pressure is shown in the Figure 7 . The command valve $\left(1 \mathrm{~V}_{1}\right)$ is in the initial position, which determines the state of the pistons in the cylinders. In this case the pistons are retracted, which means that windows are closed. From the electro-pneumatic control scheme can be seen that contacts are closed and relay $\left(\mathrm{K}_{1}\right)$ activated, which indicates all preconditions are met and $\mathrm{CO}_{2}$ sensor $\left(\mathrm{S}_{1}\right)$ can perform its function.

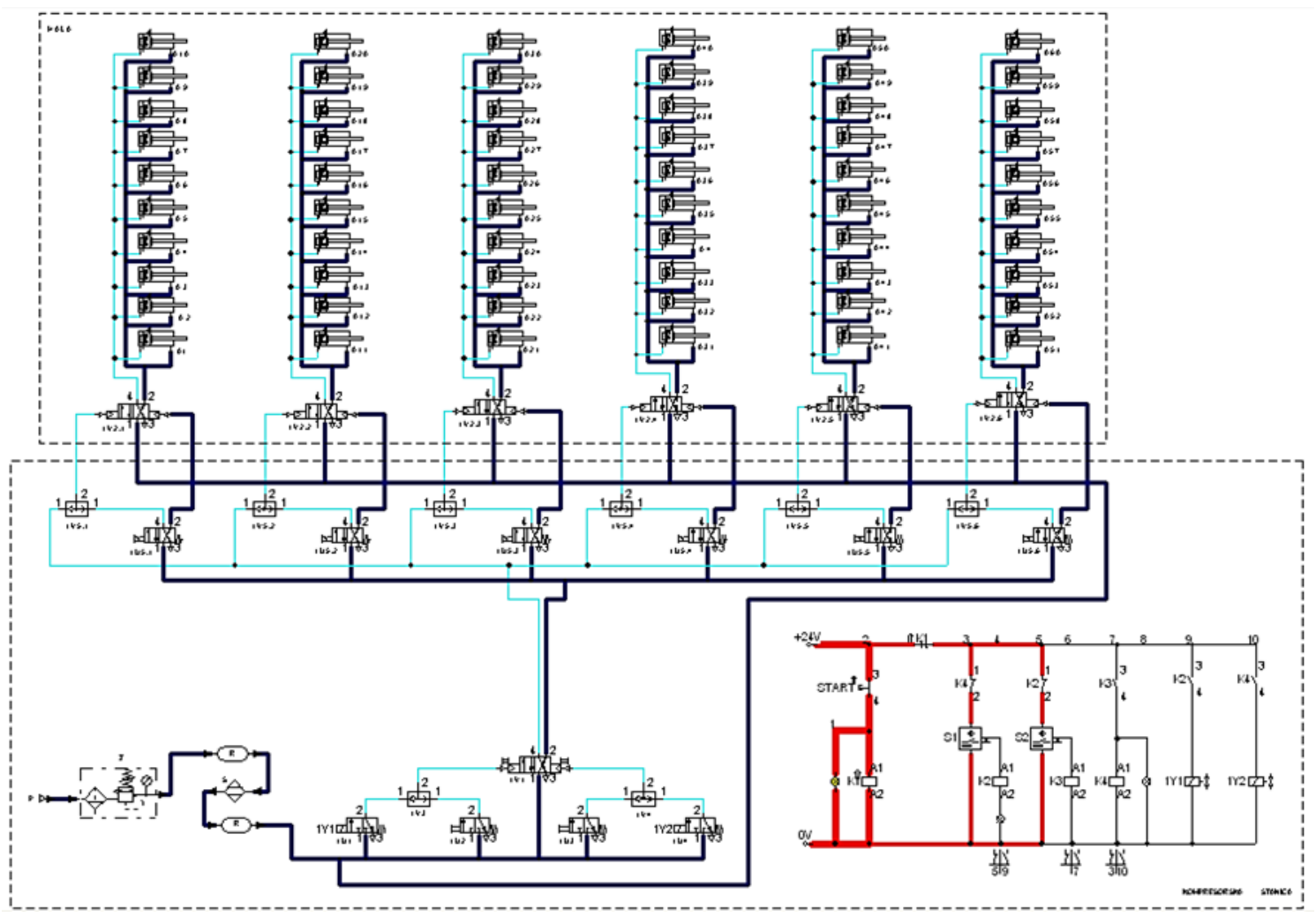

Fig. 7. Activated system under pressure

Subsequently, figure 8 shows the state of the system when a sensor $\left(\mathrm{S}_{1}\right)$ detects the set concentration of $\mathrm{CO}_{2}$. Activation of the relay $\left(\mathrm{K}_{2}\right)$ closes the contact $\left(\mathrm{K}_{2}\right)$ in $11^{\text {th }}$ branch of electro-pneumatic scheme and an electrical signal is being transmitted to the spool of the control valve $\left(1 \mathrm{U}_{1}\right)$, which in this case, by changing its position opens the passage to air toward to so called "or-function" valve $\left(1 \mathrm{~V}_{3}\right)$, changes the position of the command valve $\left(1 \mathrm{~V}_{1}\right)$, causing the cylinder 
pistons to extract (windows opening). At the same time the contact $\left(\mathrm{K}_{2}\right)$ in $7^{\text {th }}$ branch of electrical scheme is interrupted, which incapacitates sensor $\left(S_{2}\right)$ to react for a certain period of time. Likewise, figure 9 shows the state of the system when the sensor $\left(\mathrm{S}_{2}\right)$ is activated. Here, it should be noted that the system is in the state as shown in Figure 7 up to the moment of sensor $\left(\mathrm{S}_{2}\right)$ activation. Detection of predetermined $\mathrm{CO}_{2}$ concentrations by sensor $\left(\mathrm{S}_{2}\right)$, activates relay $\left(\mathrm{K}_{3}\right)$, which closes the contact $\left(\mathrm{K}_{3}\right)$ in the $9^{\text {th }}$ branch of electro-pneumatic scheme, causing the signal transmission to the relay $\left(\mathrm{K}_{4}\right)$. Activation of the relay $\left(\mathrm{K}_{4}\right)$ closes the contact $\left(\mathrm{K}_{4}\right)$ in $12^{\text {th }}$ branch of electro-pneumatic scheme and an electrical signal is transmitted to the spool of the control valve $\left(1 \mathrm{U}_{4}\right)$, forcing it to change its position and ensure the air way toward to the command valve $\left(1 \mathrm{~V}_{1}\right)$. The command valve $\left(1 \mathrm{~V}_{1}\right)$ than takes its left position, whereby compressed air is channeled into the right ventricles of cylinders, pistons retract and the windows close. At the same time the contact $\left(\mathrm{K}_{4}\right)$ in $5^{\text {th }}$ branch of electrical scheme is interrupted, which incapacitates sensor $\left(\mathrm{S}_{1}\right)$ to react for a certain period of time.

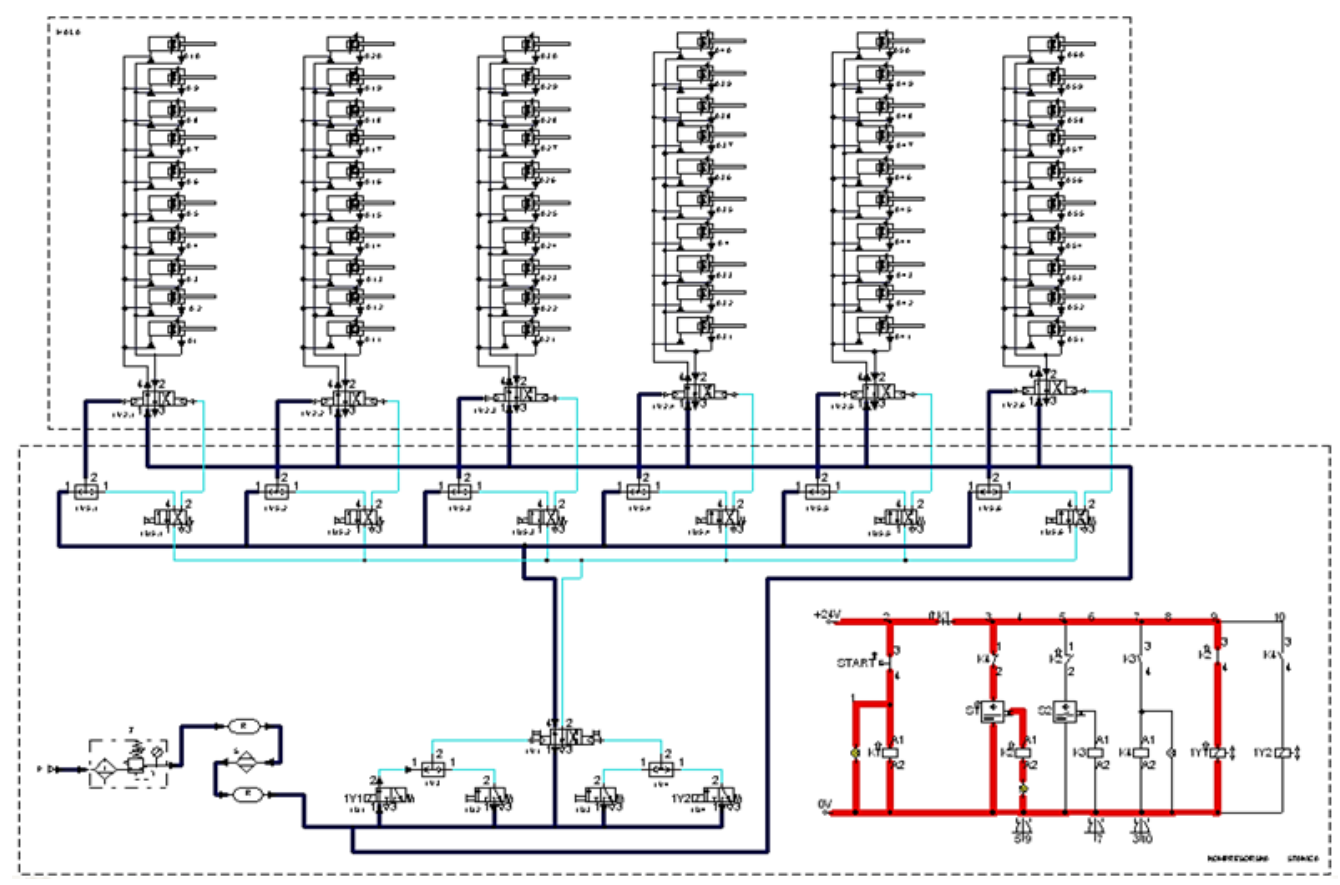

Fig. 8. System status in the activation of the sensor (S1)

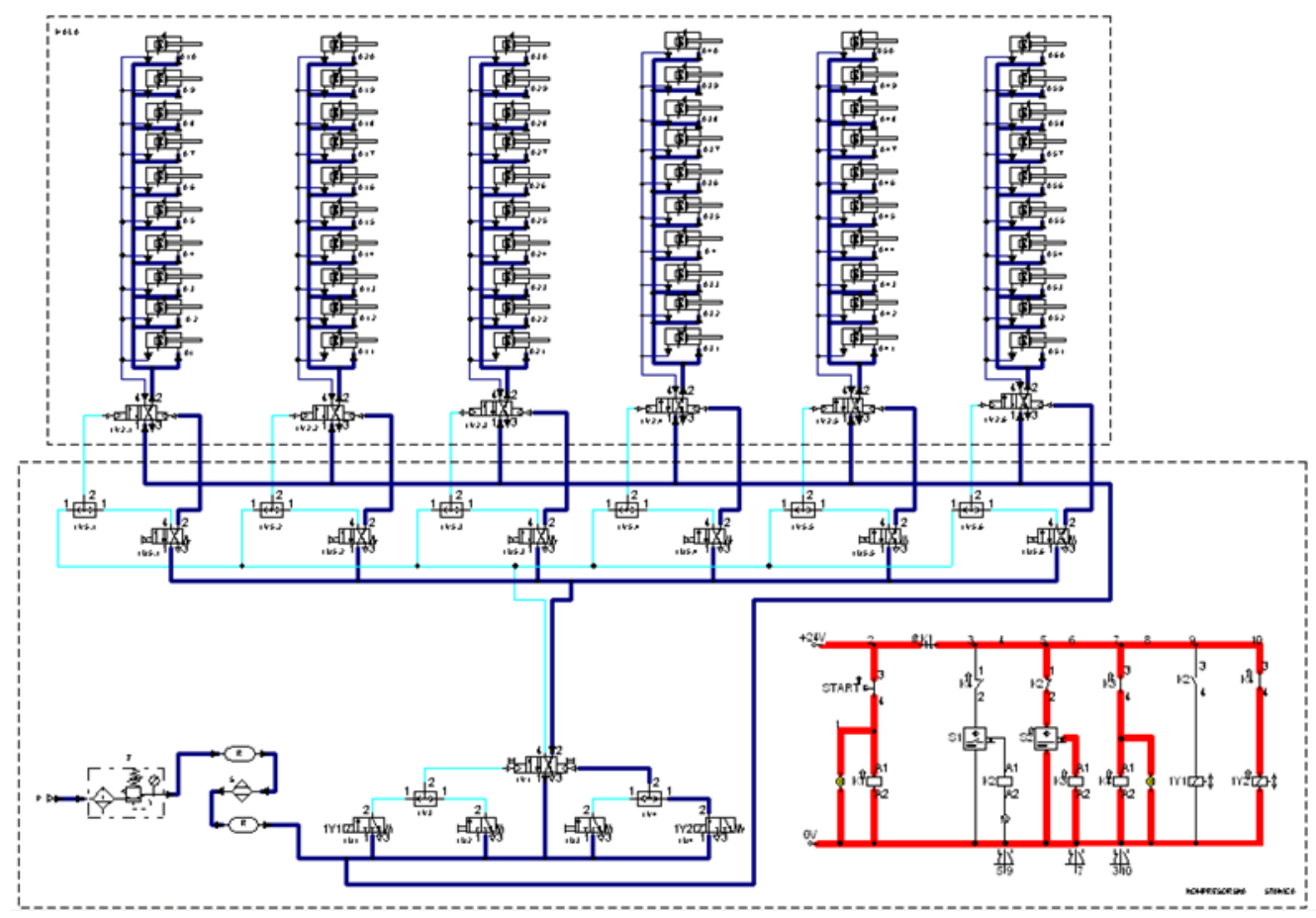

Fig. 9. System status in the activation of the sensor (S2) 


\section{Conclusion}

Conclusively, beside general good practice guides and scientific literature review regarding CAS management, paper provided analysis of specific CAS where compressed air is used as an energy source to perform work. More precisely, CAS is used to regulate natural ventilation system where pneumatic actuators control openness or closeness of large number of windows located in inaccessible location. In addition, the possible energy efficiency improvements and automation upgrade were suggested. Based upon the audit results and subsequent calculations, it was determined that the capacity of existing air reservoirs $\left(0.48 \mathrm{~m}^{3}\right)$ were not sufficient. Having in mind that recommended, analytically determined, reservoir volume should amount $0,806 \mathrm{~m}^{3}$, the setting of additional air reservoir with capacity of $0.42 \mathrm{~m}^{3}$ is proposed. Furthermore, upon ascertainment of oversized cylinders, the possible reduction in working pressure of 2 bars was estimated, which leads to significant reduction of the power consumption as the less powerful motor could be installed. This could ensure savings of at least $26.6 \%$ in electricity consumption. Investigation of energy saving solutions, which aim at the optimization of design parameters of pneumatic drives and recovery of exhaust air, should be considered in future research. Lastly, the main focus of this paper was to analyze and improve current level of CAS automation. To achieve this, an optimization model, based on electro-pneumatic control system with $\mathrm{CO}_{2}$ sensors was introduced and simulated. The proposed optimization model ensures the increase in the level of CAS automation and system energy efficiency, as well as effective functioning of natural ventilation with introduced indicators $\left(\mathrm{CO}_{2}\right.$ concentration), which are now monitored. This meets the requirement of keeping the stability of the process and suppressing the influence of disturbances. In addition, CAS automation upgrade eliminates many subjective weaknesses, shortens the time required for the execution of operation, reduce costs, and most importantly eliminates the constant need for manual control by operator. Here, elimination of human factor has significant influence because it does not affect the process of achieving results. At the end, further integration of air temperature sensors should be considered in order to achieve control system based on these two important variables.

\section{References}

[1] P. Harris, S. Nolan, G. E. O’Donnell, Energy optimisation of pneumatic actuator systems in manufacturing, Journal of Cleaner Production 72 (2014) 35 - 45.

[2] E. Rakova, J. Weber, Process simulation of energy behaviour of pneumatic drives, Procedia Engineering 106 (2015) $149-157$.

[3] AMSG, Compressed air systems market assessment, Public Service Electric and Gas Pacific Energy Associates, Final report (2001), Edison, NJ, USA.

[4] B. Joseph, Compressed air supply efficiency, IETC Conference (2004), Houston, Southern California Edison,USA.

[5] B. Joseph,Industrial compressed air supply system efficiency, California energy commission pier program, consultant report (2004).

[6] M. Hasmandova, Compressed air systems: auditing and replacing air compressors, Filtration andSeparation, November (2008) 41-3.

[7] J. Holdsworth, Conserving energy in compressed air systems, Plant Engineering 51 (13) (1997) 103-4.

[8] R. E. Terrell, Improving compressed air system efficiency - Know what you really need, EnergyEngineering 96 (1) (1999) 7-15.

[9] G. Greenough, Selecting a compressed air system, Metal Finishing 98 (6) (2000) 398-400.

[10] C. Y. Yuan, T. Zhang, A. Rangarajan, D. Dornfeld, B. Ziemba, R. Whitbeck, A decision-basedanalysis of compressed air usage patterns in automotive manufacturing, Journal of ManufacturingSystems 25 (4) (2006) 293300.

[11] D. Kaya, P. Phelan, D. Chau, H. I. Sarac, Energy conservation in compressed-air systems, InternationalJournal of Energy Research 26 (2002) 837-49.

[12] R. Saidur, N. A. Rahim, M. Hasanuzzaman, A review on compressed air energy use and energy savings, Renewable and Sustainable Energy Reviews 14 (2010) 1135-1153.

[13] R. Dindorf, Estimating Potential Energy Savings in Compressed Air Systems, XIIIth International Scientific and Engineering Conference "HERVICON-2011", Procedia Engineering 39 (2012) $204-211$.

[14] M. Medojevic, J. Petrovic, Energy Consumption of Compressed Air Systems and Potential of Heat Recovery with example, 16thSymposium on Thermal Science and Engineering of Serbia, Sokobanja, Serbia, (2013), ISBN: 97886-6055-043-1.

[15] M. Medojevic, J. Petrovic, M. Peric, Potential of heat recovery from air compressors, 44th International congres and exhibition on Heating, refrigiration and air conditioning, Belgrade (2014)ISBN 978-86-81505-75-5.

[16] Minesota Technical Assistance Program, Compressed Air Basics, The University of Minnesota, published online: http://www.mntap.umn.edu/greenbusiness/energy/compair.htm, last modified on November 22, 2013.

[17] H. Meixner, R. Kobler, Einführung in die Pneumatik - Lehrbuch Festo Didactit (prevod: Uvod u pneumatiku Udžbenik), FTN OOUR Institut za Industrijske Sisteme, Novi Sad (1977) - in Serbian.

[18] The Carbon Trust, Energy Efficient Compressed Air Systems - Good Practice Guide GPG385, London (2005).

[19] Xenergy Inc., Assessment of the Market for Compressed Air EfficiencyServices - Prepared for Oak Ridge National Laboratory and Lawrence Berkeley National Laboratory,U.S. Department of Energy Washington, DC (2001). 
[20] D. Šešlija, I. Ignjatović, S. Dudić, B. Lagod, Potential Energy Savings in Compressed Air Systems in Serbia, African Journal of Business Management, 5 (14) (2011), 5637-5645.

[21] L. Li, L. Yuqi, A. McKane, T. Taranto, Energy efficiency improvements in Chinese compressed air systems, Lawrence Berkeley National Library, University of California (eScholarship Repository 2008) Paper LBNL-63415, Permalink: http://escholarship.org/uc/item/0v72z2q0

[22] I. Sarbu, C. Sebarchievici, Aspects of indoor environmental quality assessment in buildings, Energy and Buildings 60 (2013) 410-419.

[23] L. Lan, Z. Lian, Use of neurobehavioral tests to evaluate the effects of indoor environment quality on productivity, Building and Environment 44 (2009) 2208-2217.

[24] T. Kershaw, D. Lash, Investigating the productivity of office workers to quantify the effectiveness of climate change adaptation measures, Building and Environment 69 (2013) 35-43.

[25] R. Kosonen, F. Tan, The effect of perceived indoor air quality on productivity loss, Energy and Buildings 36 (2004) 981-986.

[26] M. Košir, A. Krainer, Ž. Kristl, Integral control system of indoor environment in continuously occupied spaces, Automation in Construction 21 (2012) 199-209.

[27] J. Madureira, I. Paciencia, J. Rufo, E. Ramos, H. Barros, J. P. Teixeira, E. De Oliveira Fernandes, Indoor air quality in schools and its relationship with children's respiratory symptoms, Atmospheric Environment 118 (2015) 145-156.

[28] A. Schütze, Integrated sensor systems for indoor applications: ubiquitous monitoring for improved health, comfort and safety, Procedia Engineering 120 ( 2015 ) 492 - 495.

[29] V. Koppar, R. M. Lathe, P. Siddharam, Automation of a Planer Using Electropneumatic Devices and Programmable Logic Controller, International Journal of Engineering Research and Development 7 (11) (2013), 18-25.

[30] Y. Fan, K. Kameishi, S. Onishi, K. Ito, Field-based study on the energy-saving effects of CO2 demand controlled ventilation in an office with application of Energy recovery ventilators, Energy and Buildings 68 (2014) 412-422.

[31] Y. You, C. Niu, J. Zhou, Y. Liu, Z. Bai, J. Zhang, F. He, N. Zhang, Measurement of air exchange rates in different indoor environments using continuous CO2 sensors, Journal of Environmental Sciences 2012, 24 (4) $657-664$. 